\title{
A STRAIN DEPENDENT STIFFNESS OF STIFF COHESIONLESS AND COHESIVE SOILS
}

\author{
MirosŁaW J. LiPiŃSKi, MAŁgorZATA K. WdowsKA \\ Faculty of Civil and Environmental Engineering, \\ Department of Geotechnical Engineering, Warsaw University of Life Sciences - SGGW, \\ ul. Nowoursynowska 159, 02-776 Warszawa, Poland, \\ e-mail: miroslaw.lipinski@wp.pl; malgorzata.wdowska@wp.pl
}

\begin{abstract}
In the last three decades an interest has grown in prediction of soil stiffness. In case of dense cohesionless soils or natural overconsolidated cohesive soils the working strain to which soil stiffness is referred to covers the range $0.01-1.0 \%$. On the basis of results of comprehensive experimental worked based on advanced triaxial tests results two formulae for Young's modulus distribution accounting for strain range were derived for fine dense sand and heavy overconsolidated sandy clay. The formula for sand accounts also for stress level. In case of overconsolidated sandy clay, stress history, in the form of yield stress, is also accounted for.
\end{abstract}

\section{INTRODUCTION}

The major limitation in the design in geotechnical practice is usually associated with serviceability limit state which is controlled by stiffness parameters, among which Young's modulus is the most often used. Unfortunately, quantitative evaluation of its characteristic value must account for many variables contributing to the soil stiffness. For a given soil, the most eminent variable is a working strain range to which the modulus is referred to. Irrespective other parameters, stiffness is always strain dependent since a stress-strain characteristic in soils is always nonlinear. This concerns cohesionless and cohesive soils as well. The second very important variable is associated with soil state. In this case, description of soil state in cohesionless soils is significantly different than in cohesive ones. It results from the fact that in cohesionless soils there is no unique compressibility line. The major factors which contribute to state of cohesionless soil is initial void ratio and state of stress. In case of cohesive soil it is acquired stress history with all associated postdiagenesis processes and current state of effective stress. Unfortunately, this issue is poorly understood, since existing empirical correlations refer to a particular soil with known mechanical preconsolidation stress. Such situation, although interesting with respect to research point of view, it is of little practical significance, since stress history parameter should refer to natural soils. In any case, these above mentioned variables contribute to the largest extent to soil stiffness in all soils. Qualitatively it can be described by two diagrams shown in Figure 1 which reflect an importance of strain range and state of soil in description of soil stiffness for cohesionless and cohesive soil. The authors realize the 
obvious subjectivity of these diagrams, however, they are intended to show the importance of the subject. Besides, in geotechnical literature, there is no solution accounting for these two aspects with satisfactory level of confidence. The rationale of this paper is to present an approach to description of soil stiffness in a wide range of strain in typically encountered in Poland representative soils, i.e., fine sand and silty clay. In case of natural cohesive soil the proposed description accounts also for stress history.

Cohesionless soils

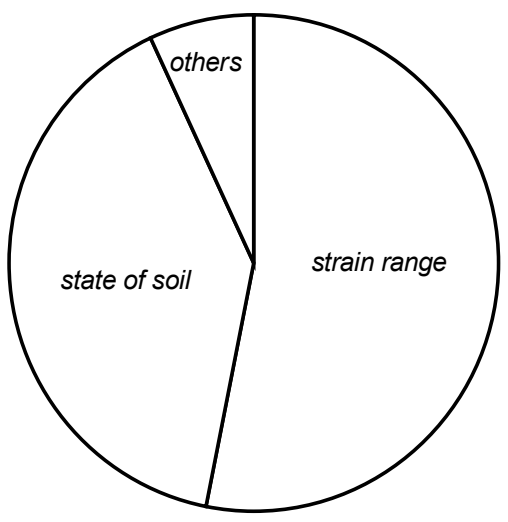

Cohesive soils

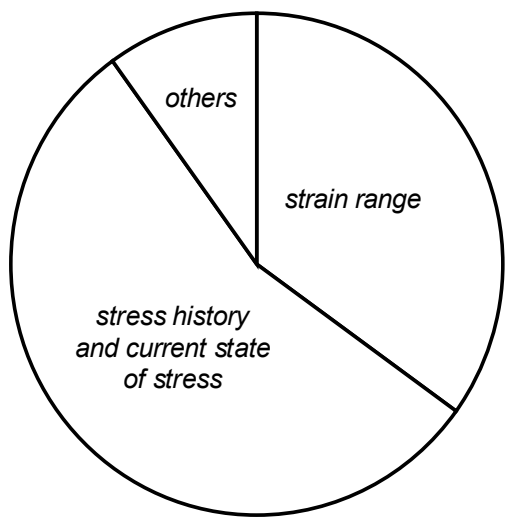

Fig. 1. Qualitative grading of variables contributing to stiffness of cohesionless and cohesive soils

\section{A KEY VARIABLES CONTRIBUTING TO STIFFNESS}

\subsection{STRAIN RANGE}

In spite of the fact that soils response to loading rarely (if at all) can be considered elastic, it is known that in a certain range of strain soils reveal true elastic behaviour. It should be emphasized that term "elastic" is ambiguous for such nonlinear behaviour as it is in case of soil. Early works by Hardin and Black (1968) concerning response of soil to dynamic loading showed very small hysteresis loop under cyclic loading in a strain range not exceeding $0.01 \%$. On the other hand, in monotonic tests, a strain range in which elastic behavior is observed is smaller and its upper limit is usually described as $0.001 \%$ (e.g., Jardine et al. 1984). If these ranges of elastic behaviour were to be respected, then models describing the soil response would have to be very complex. However, if the elastic strain limit was shifted in direction of larger strain then soil behaviour would be described as hypoelastic and Young's moduli would take secant values and strain would not be recoverable in a full range. Such approach is practically very convenient and its example of theoretical adequacy is Cam-Clay Model in which inside a yielding surface a material is considered elastic. Such a sim- 
plified assumption appears to be very attractive with respect to practical applications since for tunnels, foundations and walls working strain range refers to $5 \cdot 10^{-3} \div 5 \cdot 10^{-1} \%$ (Mair 1993). Taking the above into consideration it is stated that use of Young's modulus for soil stiffness description is absolutely justified, although it must be kept in mind that range of strain should be always accounted for.

\subsection{STRESS COMPONENTS AND STRESS HISTORY IN COHESIVE SOILS}

Analysis of Young's modulus variability should account for all factors contributing to its value. Besides the above described importance of strain range, one must not disregard another two factors which are stress history and stress level. Certainly, both values refer to effective stress state. It is worth to notice that stress level and stress history are in a way coupled and therefore in order to account for both values, stiffness parameter has to be normalized with respect to one of them. Such approach has been used in soil mechanics for many years. The most eminent example are: Critical State Soil Mechanics born in Cambridge in late 1950s and 1960s and SHANSEP procedure (1974) which originated from MIT. In both cases a soil parameter was normalized with respect to effective stress. This approach has been proved to be useful not only because of its simplicity but also it contributed to better understanding of soil behaviour under loading. It allows to separate increase in soil stiffness resulting from stress history from that which results from stress level increase. This is very important for description of soil stiffness change, and will be addressed in this paper in paragraph concerning cohesive soils.

\section{YOUNG'S MODULUS DISTRIBUTION FOR COHESIONLESS SOIL}

In case of a given cohesionless soil any description of soil stiffness should account for strain range and state of soil consisting of void ratio and mean effective stress. As a representative soil, a fine sand was used which is very often encountered in Poland during realization of geotechnical works. The soil has $92 \%$ of fraction retaining on ASTM sieve \#200, i.e., corresponding to diameter $0.075 \mathrm{~mm}$ and diameter $d_{50}=0.17 \mathrm{~mm}$. The soil was reconstituted in triaxial apparatus by moist tamping technique to dense state corresponding to narrow void ratio range $0.614-0.624$. There are at least two reasons that a dense sand was selected. The first one is that in case of cohesionless material in Poland this state definitively prevails. The second one comes from the fact that one of the component of the state should be fixed to allow the other (effective stress) to be a variable.

In the triaxial apparatus reconstituted specimens were saturated and consolidated anisotropically to various mean effective stress. And the end of consolidation, drained shearing stage commenced with vertical stress path imposed (i.e., increasing deviatoric stress $\Delta q>0$ and $\Delta p^{\prime}=0$ ). A series of eight tests which fulfilled conditions described above were used for the further analysis. 
As it was already mentioned, three major variables contribute to a stiffness of soil: strain range, stress state and density. Since the third variable was fixed, the other two must be represented in a postulated equation. At the beginning, the assumption was made that function describing Young's modulus distribution takes the following form:

$$
E=\frac{B}{\varepsilon^{n}}
$$

where:

$\varepsilon$-axial strain,

$B, n$-empirical fitting parameter.

The first step in setting up the formula for Young's modulus consisted in establishing a regression between the modulus and mean effective stress. It is quite obvious that such a relationship will depend on strain level therefore it was necessary to refer any obtained correlation to particular level of strain range. The following strain ranges were distinguished:

$$
\varepsilon_{1}=0.01 \%, \quad \varepsilon_{1}=0.02 \%, \quad \varepsilon_{1}=0.05 \%, \quad \varepsilon_{1}=0.1 \%, \quad \varepsilon_{1}=0.2 \%, \quad \varepsilon_{1}=0.5 \% .
$$

The selected values of strain cover the range $0.01-0.5 \%$ which is of most interest in engineering applications. The above correlations between Young's modulus and mean effective stress for each of the above strain range category were shown in Figure 2. It is worth to note that in a wide range of mean effective stress (117-903 kPa) the obtained relationships can be approximated by linear regressions.

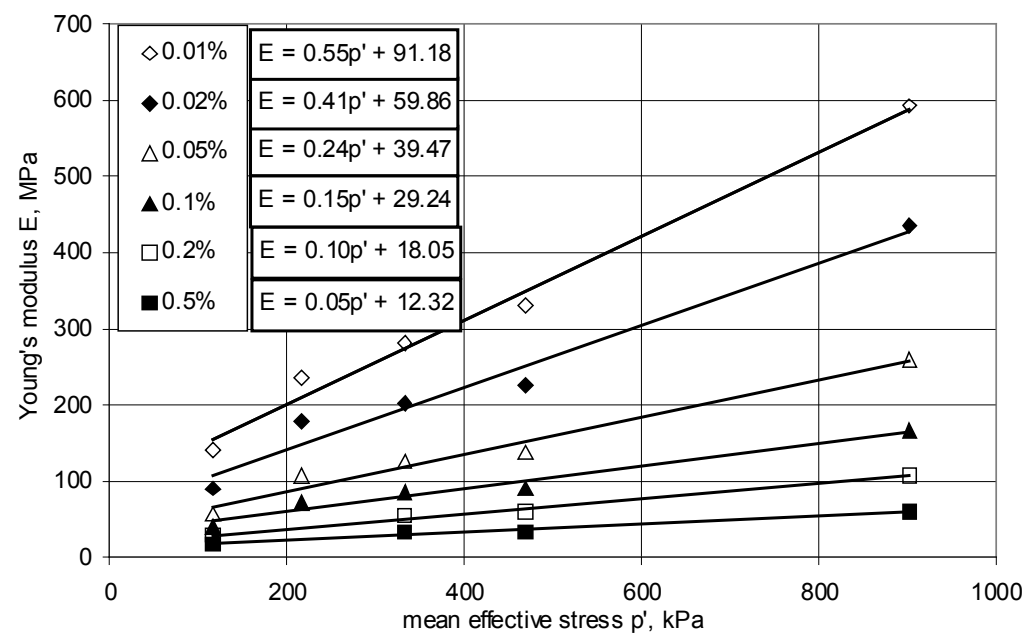

Fig. 2. Correlation between Young's modulus and mean effective stress for various strain level. Dense fine sand 
Having obtained the regressions relating Young's modulus to mean effective stress in various strain range categories it is possible to pass to the next stage which is to look for $B$ parameter of the assumed formula. To realize this it was necessary to see how regressions obtained from chart in Figure 2 plot against vertical strain. Similarly, as in the case of the previous chart these regressions were determined for different categories of variable not represented at the axes of the chart, i.e., eight values of mean effective strain. The result of these correlation together with resulting equations are shown in Figure 3. Besides the obtained $B$ parameter for each value of specified mean effective stress it is worth to make two observations. The first one concerns range of strain in which the stiffness of soil exerts the highest nonlinearity.

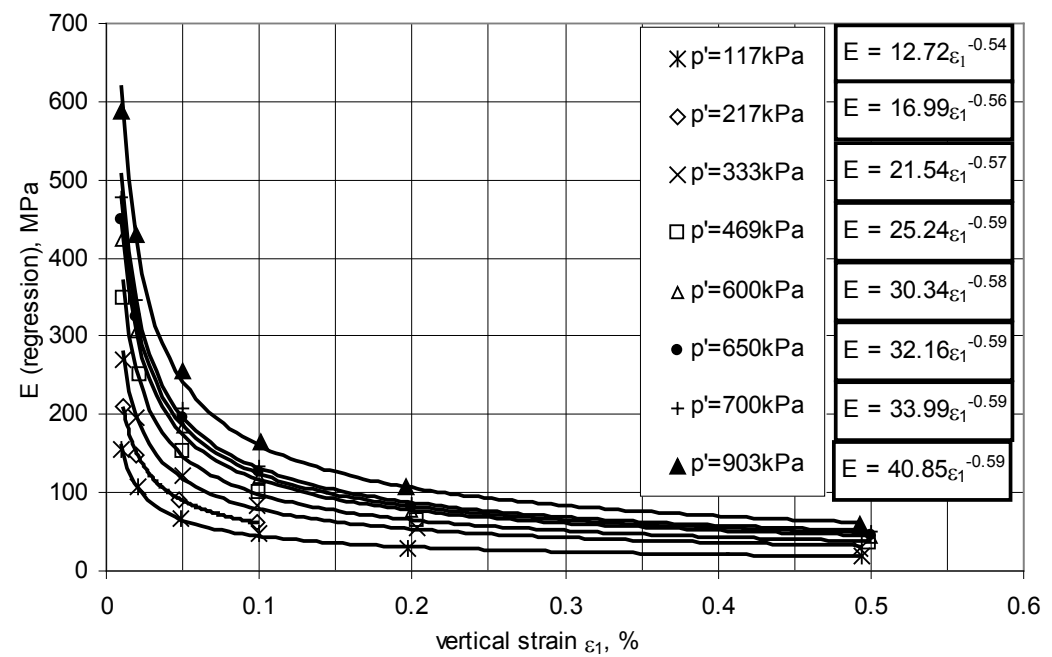

Fig. 3. Correlation between Young's modulus and vertical strain for various mean effective stress levels. Dense fine sands

Depending on the stress level the highest nonlinearity limit strain is in the range $0.1-0.2 \%$. It is worth to note that this strain range is much smaller than it could have be expected by a designer. The second observation concerns influence of stress level on "nonlinearity" strain range. The charts reveal that higher the stress less nonlinear is stiffness distribution and the range of "highest nonlinearity" is bigger. For mean effective stress around $100 \mathrm{kPa}$ the most nonlinear stiffness distribution ends at $0.1 \%$, while for stress 9 times higher this strain range is doubled. Empirical fitting parameters in equations shown in Figure 3 actually determines influence of mean effective stress and strain range on Young's modulus distribution. For getting more information concerning change of these parameters against the above mentioned variables it is necessary to prepare another plots. The first one, which is depicted in Figure 4, shows how $B$ parameter plots against mean effective stress. In spite of the fact that stress 
range is wide the obtained data can be conveniently approximated by linear regression with high level of confidence. The second plot describes how exponent $n$ changes with stress. A chart shown in Figure 5 reveals hyperbolic increase in $n$ value against mean effective stress. In more refined analysis, distribution of parameter $n$ against mean effective stress should be accounted for. However, it is should be also noticed that range of $n$ value change is rather small, and does exceeds 0.05 . This observation is of practical importance because it allows in simplified application to use average value. Thus the final formula is considerably simplified. Assuming average value of fitting parameter $n=0.57$ the formula for Young's modulus distribution takes the following form:

$$
E=\frac{b+a\left(p^{\prime}-p_{r e f}\right)}{\varepsilon^{n}}=\frac{12.3+35.38\left(p^{\prime}-0.1\right)}{\varepsilon^{0.57}}
$$

where:

$p^{\prime}$ - mean effective stress [MPa],

$p_{\text {ref }}-$ reference mean effective stress taken as $0.1[\mathrm{MPa}]$,

$\varepsilon-$ vertical strain $[\%]$.

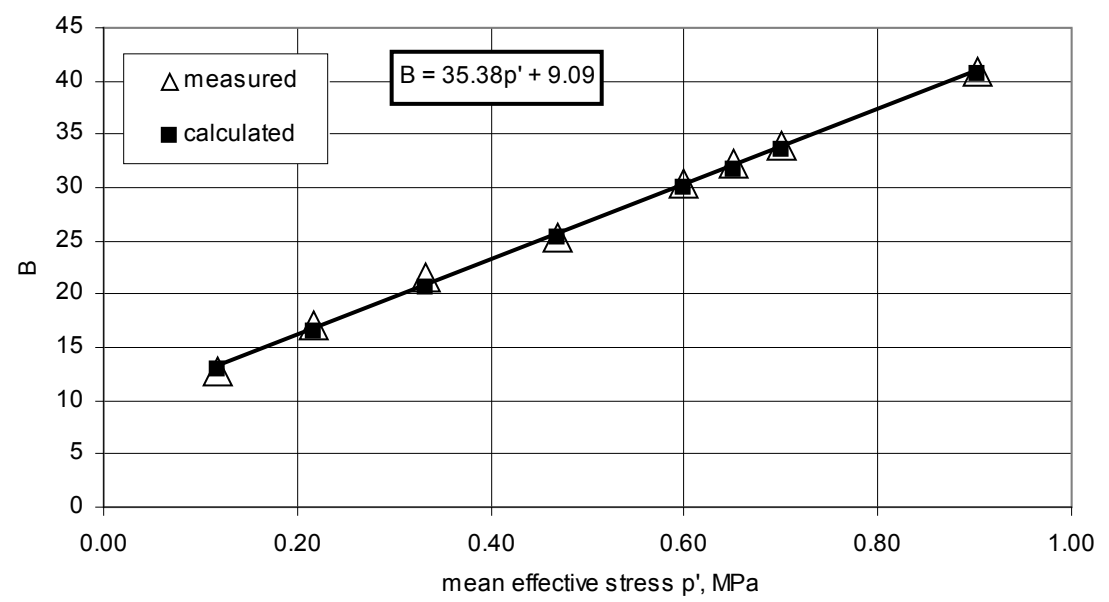

Fig. 4. Change of fitting parameter $B$ with mean effective stress. Dense fine sands

Verification of the above formula can be accomplished by comparison of calculated values of Young's modulus with use of the above formula and $E$ measured during tests. Such a comparison is shown in Figure 6. To facilitate a comparison an equal moduli line is added at the chart. A quick glance on the chart reveals that the formula quite well estimates a stiffness of the soil represented by Young's modulus. This refers to intermediate stress being in the range 200-500 kPa, i.e., very common in engineering applications. The stiffness for smaller values of mean effective stress (around $100 \mathrm{kPa}$ ) is overestimated while for higher values (around $900 \mathrm{kPa}$ ) is un- 
derestimated. This deviation from the perfect fit is a clear consequence of the assumption to accept average value for exponent $n$. In case of more refined analysis it seems that for higher and lower stresses the exponent should be taken from the chart in Figure 5.

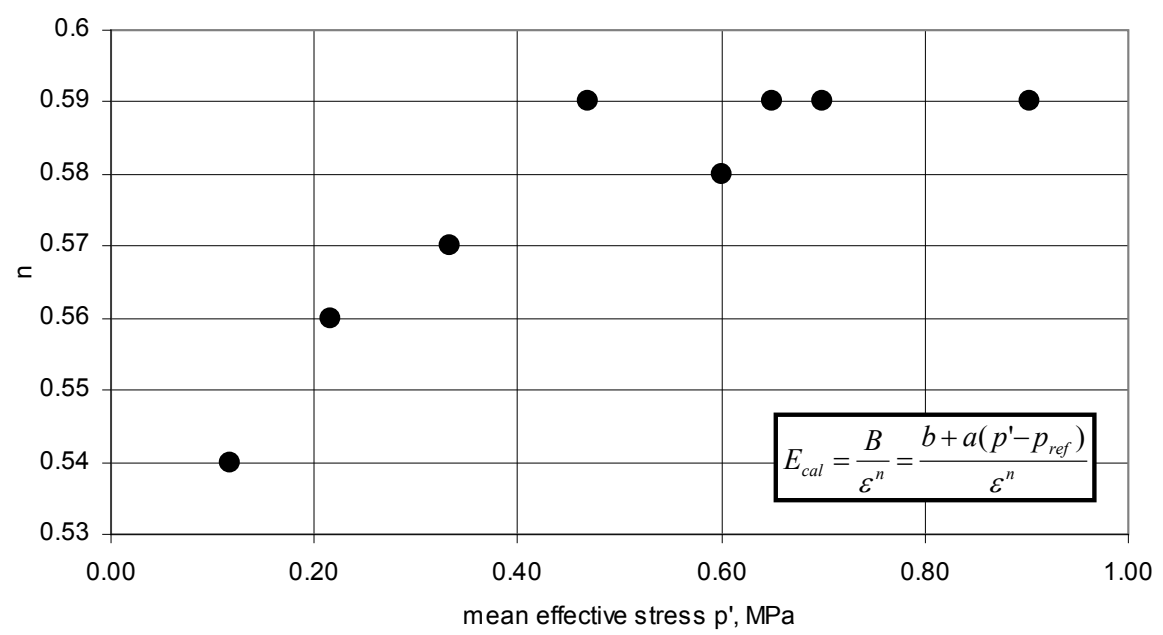

Fig. 5. Change of fitting exponent $n$ with mean effective stress. Dense fine sands

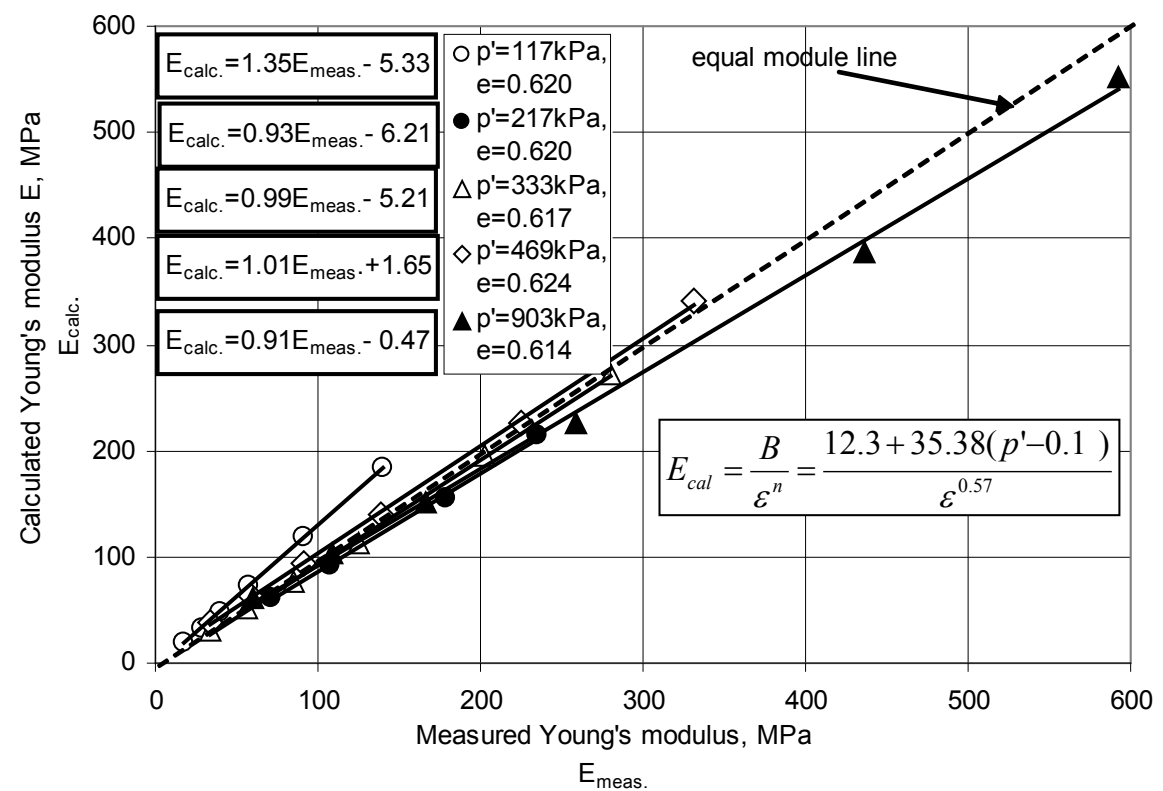

Fig. 6. Calculated vs. measured Young's modulus for dense fine sand 


\section{STIFFNESS DISTRIBUTION OF COHESIVE SOILS}

\subsection{RECONSTITUTED SOILS OF KNOWN STRESS HISTORY}

The first step in description of Young's modulus distribution consisted in carrying out series of tests on soils with known history. In order to do this it was necessary to prepare slurry material from soil which previously was tested in its natural state. Basic index properties of reconstituted and natural material are presented in Table 1.

Table 1

Index properties of tested materials

\begin{tabular}{|c|c|c|c|c|c|c|c|}
\hline \multicolumn{1}{|c|}{$\begin{array}{c}\text { Undisturbed (natural) samples } \\
\text { depth }\end{array}$} & $\begin{array}{c}\text { clay } \\
\text { friction }\end{array}$ & $\begin{array}{c}\text { water } \\
\text { content }\end{array}$ & $\begin{array}{c}\text { liquid } \\
\text { limit }\end{array}$ & $\begin{array}{c}\text { plastic } \\
\text { limit }\end{array}$ & $\begin{array}{c}\text { index of } \\
\text { plasticity }\end{array}$ & $\begin{array}{c}\text { consistency } \\
\text { index }\end{array}$ & $p^{\prime}$ \\
\hline$[\mathrm{m}]$ & {$[\%]$} & {$[\%]$} & {$[\%]$} & {$[\%]$} & {$[\%]$} & {$[-]$} & {$[\mathrm{kPa}]$} \\
\hline $6.0 \div 8.5$ & $13 \div 19$ & $11.8 \div 14.2$ & $19.7 \div 22.4$ & $9.5 \div 11.7$ & $9.9 \div 12$ & $0.72 \div 0.81$ & $\begin{array}{c}80 \\
200400\end{array}$ \\
\hline \multicolumn{7}{|c|}{ Reconstituted material - initial state } \\
\hline OCR & $\begin{array}{c}\text { clay } \\
\text { friction }\end{array}$ & $\begin{array}{c}\text { water } \\
\text { content }\end{array}$ & $\begin{array}{c}\text { liquid } \\
\text { limit }\end{array}$ & $\begin{array}{c}\text { plastic } \\
\text { limit }\end{array}$ & $\begin{array}{c}\text { index of } \\
\text { plasticity }\end{array}$ & $\begin{array}{c}\text { consistency } \\
\text { index }\end{array}$ & $p^{\prime}$ \\
\hline$[-]$ & {$[\%]$} & {$[\%]$} & {$[\%]$} & {$[\%]$} & {$[\%]$} & {$[-]$} & {$[\mathrm{kPa}]$} \\
\hline $1 ; 2 ; 3 ; 4 ; 5 ; 8$ & 16 & 20.6 & 21.6 & 10.8 & 10.8 & 0.09 & 80 \\
\hline
\end{tabular}

In order to obtain soil of various stress history, each specimen was preconsolidated mechanically to predetermined value of isotropic stress. As a reference stress, at which the soil was sheared, value of $80 \mathrm{kPa}$ was settled. In order to obtained mechanically preconsolidated soil of different $O C R$ each specimen was first consolidated to various effective stress from the range $80-640 \mathrm{kPa}$. Then, when consolidation stage was terminated the soil was unloaded to $80 \mathrm{kPa}$. Thus the following $O C R$ values were obtained 1, 2, 3, 4, 5 and 8 . Having prepared specimens for shearing according to the above described procedure the soil specimens were sheared in undrained conditions with standard stress path induced. It is worth to emphasize that values of Young's modulus obtained on the basis of the shearing stage refer to undrained conditions.

In order to obtain relationship between stiffness and stress history for reconstituted material the data from shearing were shown in Figure 7 as normalized Young's modulus against $O C R$.

For each specimen, value of Young's modulus was determined at the following six strain levels expressed in \%: $0.01,0.02,0.05,0.1,0.5,1.0$, thus one series of tests corresponding to one stress level consists of six points, since there six values of $O C R$ are distinguished. The points for one stress level can be approximated by regression in the form of power function: 


$$
\left(\frac{E}{\sigma^{\prime}}\right)_{K O C}=\left(\frac{E}{\sigma^{\prime}}\right)_{N C} \cdot O C R^{n_{r}}
$$

where:

index $N C$ means that a soil is normally consolidated while index $K O C$ stands for known overconsolidation.

$\left(\frac{E}{\sigma^{\prime}}\right)_{K O C}-$ normalized Young's modulus for mechanically overconsolidated soil (known value of $O C R$ ),

$\left(\frac{E}{\sigma^{\prime}}\right)_{N C}-$ normalized Young's modulus for normally consolidated soil,

OCR - overconsolidation ratio,

$n_{r} \quad-$ empirical fitting parameter for reconstituted soil.

For the above specified strain levels the relevant exponent value are the following:

$\begin{array}{ll}\varepsilon_{0.01 \%} & n_{r}=0.71, \\ \varepsilon_{0.02 \%} & n_{r}=0.89, \\ \varepsilon_{0.05 \%} & n_{r}=0.96, \\ \varepsilon_{0.1 \%} & n_{r}=0.96, \\ \varepsilon_{0.5 \%} & n_{r}=0.97, \\ \varepsilon_{1.0 \%} & n_{r}=0.99 .\end{array}$

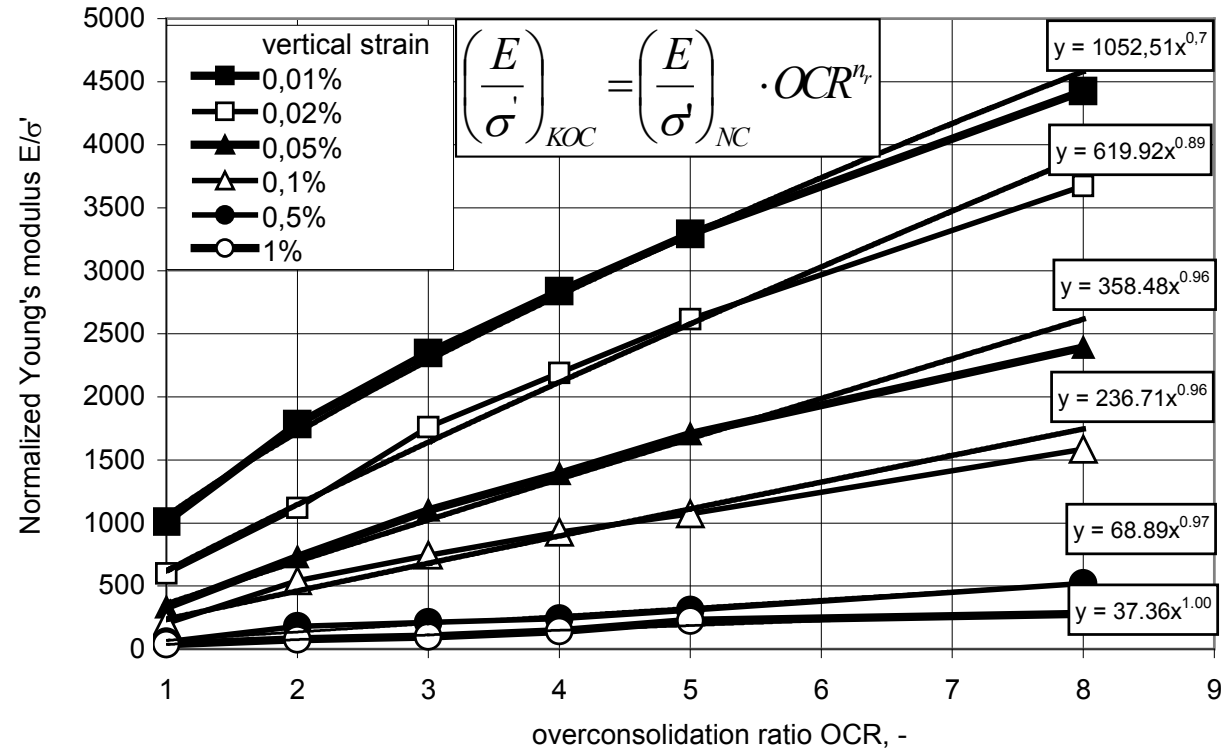

Fig. 7. Normalized Young's modulus against $O C R$ of reconstituted sandy clays 
The chart in Figure 7 clearly indicates that influence of stress history on normalized Young's modulus is coupled with strain level to which the modulus is referred to. If one accounts for definition of overconsolidation ratio then equation (3) can be rewritten in the following form:

$$
\left(\frac{E}{\sigma^{\prime}}\right)_{K O C}=\left(\frac{E}{\sigma^{\prime}}\right)_{N C} \cdot \sigma_{v}^{\prime-n_{r}} \cdot \sigma_{p}^{\prime n_{r}} .
$$

This formula clearly shows to what extent various factors contribute to stiffness of soil. Another advantage of the formula is a verification of value of normalized Young's modulus for normally consolidated soil. This verification comes from the fact that every test for various $O C R$ value is independent from the others. The analysis of chart shown in Figure 7 proves that extrapolation of regressions of points for each specified strain level for all overconsolidated specimens confirms normalized modulus value for $N C$ soil. This enhanced reliability of normalized modulus for $N C$ soil is of great importance since its value is crucial for formulation of analogous description for natural soils.

\subsection{NATURAL SOILS OF UNKNOWN STRESS HISTORY}

The principal premise for description of stiffness in natural soil was an analogy to formula of mechanically overconsolidated soil. The major difference between these soils consists in change of preconsolidation stress $\sigma_{p}$ to yielding stress $\sigma_{y}$ and exchange of empirical fitting parameter for reconstituted soil $n_{r}$ to its equivalent $n_{n}$ for natural soil. This analogy results also in a certain consequence which rests in a fact that when effective vertical stress $\sigma_{v}$ reaches value of yielding stress $\sigma_{y}$ then normalized Young's modulus equals to respective value obtained for reconstituted material with no stress history ( $N C$ soil). It is worth to notice that this assumption includes the difference between preconsolidation stress $\sigma_{p}$ and yield stress $\sigma_{y}$. Since this issue has not been commonly enlightened among geotechnical engineers so far it is worth to explain at least some background of the situation.

Many difficulties in application of standard oedometer procedures of determination of stress history in soils created much interest in phenomena which might contribute to the actual value of preconsolidation stress. As indicated by Jamiolkowski et al. (1985), a value of preconsolidation stress resulting from mechanical overburden, can be changed by many postdepositional processes like secondary compressibility, cementation, aging, temperature change and others. Many problems with quantitative description of preconsolidation phenomenon created premises for making a certain order in nomenclature. Burland (1990) proposed that the term "preconsolidation pressure" should be reserved for situations in which the magnitude of such a pressure can be established by geological means. Similarly, the term "overconsolidation ratio" should 
be reserved for describing mechanically induced, usually known stress history. In case of natural soils, where we do not know cumulative effect of mechanical prestress and other postdepositional phenomena the relevant term for stress corresponding to breakdown in a stress strain curve is "yield stress". In this case the ratio between it and the effective overburden stress $\left(\sigma_{y} / \sigma_{v 0}\right)$ could be termed "yield stress ratio". These terms are typical for cohesive natural soils. In spite of the fact that Burland's proposal introduced a certain semantic order in nomenclature, a reliability of identification of yield stress in natural soils have not changed. It should be emphasized here that any laboratory procedure based on oedometer tests does not provide a realistic value of yield stress, especially in heavy preconsolidated soils. In such situation there is an evident need to work out an alternative method which would not have all drawbacks inherently associated with oedometer tests and which would be capable to determine effectively the actual yield stress. Such an alternative method has been worked out by authors. A new approach is based on triaxial test which is much more modern and versatile than the oedometer test. The new concept is based on dilatancy phenomenon which takes place during shearing of dense soil. The new method has been described by Wdowska (2010). It is important to emphasize that yield stress is not a preconsolidation stress and new method is capable to determine the former one. Therefore in relation to determination of soil stiffness of natural soils if normalized Young's modulus achieves value of normalized stiffness for normally consolidated soils that means that effective normal stress exceeded value of the yield stress.

In order to derive a formula for stiffness of natural soils, three series of tests ( 3 tests in one series, together 9 tests) have been carried out on natural soils of similar grain size distribution and position on Casagrande chart as reconstituted material. Samples were consolidated at 80,200 and $400 \mathrm{kPa}$, which reflects typical stress range for majority of practical problems. To enhance representativeness of the data, the average of 3 values of modulus determined at one stress level was taken for further analysis. The results of these tests were presented in Figure 8 in the analogous way as for reconstituted material (Figure 7). However, since data concerns natural soils, on horizontal axis of the chart is vertical effective stress instead of $O C R$ as for reconstituted material. Similarly, as for reconstituted material, normalized Young's modulus was presented for six strain levels. Curves on the charts were created in such way that besides three points for natural material the fourth point represents normalized Young's modulus for effective stress equal to yield stress. Taking advantage of the equation 8 , the data were fitted with curves which describe distribution of normalized Young's modulus for natural sandy clays. The equations for six strain levels are the following:

$\varepsilon_{0.01 \%}$

$$
\left(\frac{E}{\sigma^{\prime}}\right)_{O C}=\left(\frac{E}{\sigma^{\prime}}\right)_{N C} \cdot \sigma_{v}^{\prime-0.01} \cdot \sigma_{Y}^{\prime 0.01},
$$




$$
\begin{aligned}
& \varepsilon_{0.02 \%} \\
& \left(\frac{E}{\sigma^{\prime}}\right)_{O C}=\left(\frac{E}{\sigma^{\prime}}\right)_{N C} \cdot \sigma_{v}^{\prime-0.057} \cdot \sigma_{Y}^{\prime 0.057} \\
& \left(\frac{E}{\sigma^{\prime}}\right)_{O C}=\left(\frac{E}{\sigma^{\prime}}\right)_{N C} \cdot \sigma_{v}^{\prime-0.136} \cdot \sigma_{Y}^{\prime 0.136}, \\
& \varepsilon_{0.1 \%} \quad\left(\frac{E}{\sigma^{\prime}}\right)_{O C}=\left(\frac{E}{\sigma^{\prime}}\right)_{N C} \cdot \sigma_{v}^{\prime-0.199} \cdot \sigma_{Y}^{\prime 0.199} \\
& \varepsilon_{0.5 \%} \quad\left(\frac{E}{\sigma^{\prime}}\right)_{O C}=\left(\frac{E}{\sigma^{\prime}}\right)_{N C} \cdot \sigma_{v}^{\prime-0.357} \cdot \sigma_{Y}^{\prime 0.357}, \\
& \varepsilon_{1.0 \%} \quad\left(\frac{E}{\sigma^{\prime}}\right)_{O C}=\left(\frac{E}{\sigma^{\prime}}\right)_{N C} \cdot \sigma_{v}^{\prime-0.385} \cdot \sigma_{Y}^{\prime 0.385} .
\end{aligned}
$$

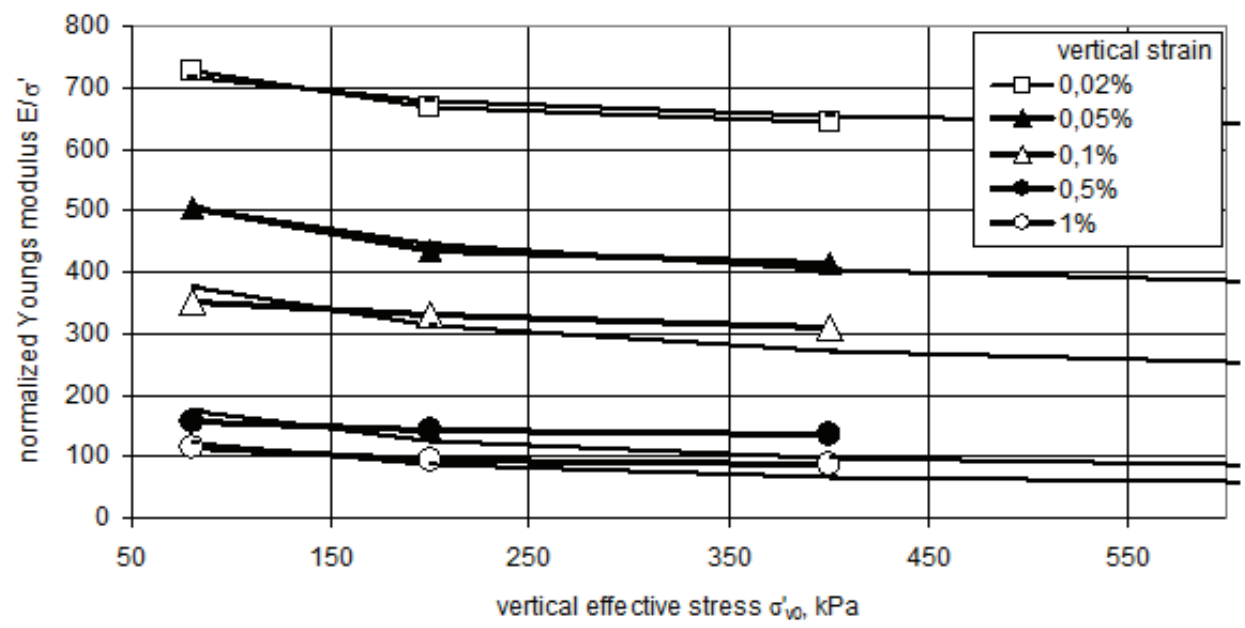

Fig. 8. Normalized Young's modulus against vertical effective stress for undisturbed sandy clays

The equations (5)-(10) are different from those for reconstituted material of known stress history. The differences concern empirical fitting parameters $\left(n_{n}\right.$ instead $\left.n_{r}\right)$ and value of preconsolidation stress was substituted by yield stress. The yield stress, determined with use of the mentioned dilatancy based method in triaxial tests was established at level $1750 \mathrm{kPa}$.

As it results from equations (5)-(10) normalized Young's modulus depends to large extent on strain levels. It is reflected by value of empirical fitting parameters $n_{n}$, 
which depend on vertical strain in very nonlinear manner, especially for strain lower than $0.3 \%$. Distribution of empirical fitting parameters for natural soils $n_{n}$ against vertical strain is shown in Figure 9. These data can be approximated by logarithmic function:

$$
n_{n}=0.08 \ln \varepsilon+0.4
$$

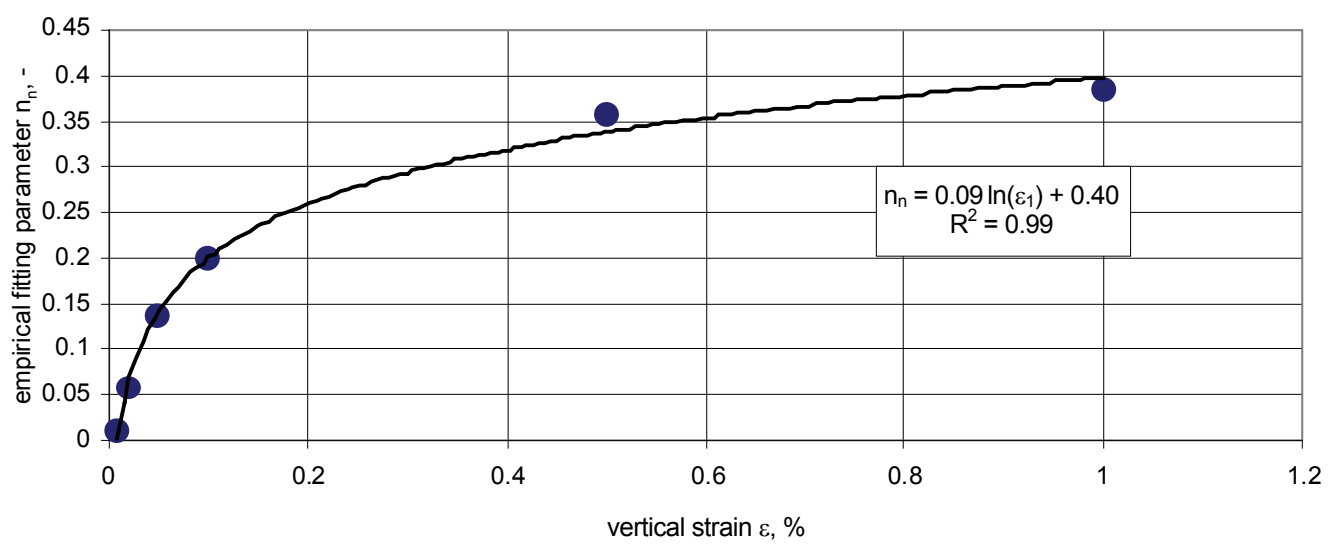

Fig. 9. Change in empirical fitting parameter against vertical strain for undisturbed sandy clays

Values of strain should be put in percents. It is worth to emphasize that standard deviation of fitting curve is very small, what means that the obtained regression reflects the trend of the data very well.

If equation 11 is combined with equations (5)-(10) the resulting formula is capable to describe Young's modulus for natural overconsolidated sandy clays in the following form:

$$
(E)_{O C}=\left(\frac{E}{\sigma^{\prime}}\right)_{N C} \cdot \sigma_{v}^{\prime 1-(0.08 \ln \varepsilon+0.4)} \cdot \sigma_{Y}^{\prime(0.08 \ln \varepsilon+0.4)} .
$$

The above formula takes into account the key variables contributing to Young's modulus value which are:

- vertical effective stress,

- yielding stress,

- vertical strain range.

In order to verify effectiveness of the above formula it is worth to compare modules calculated on the basis of the derived formula with measured values of Young's modules. The results of such comparison is shown in Figure 10. The chart clearly shows that the derived formula describes stiffness of soil very well, slightly underes- 
timates Young's modules for vertical stress lower than $100 \mathrm{kPa}$ and little overestimates them for higher vertical effective stress.

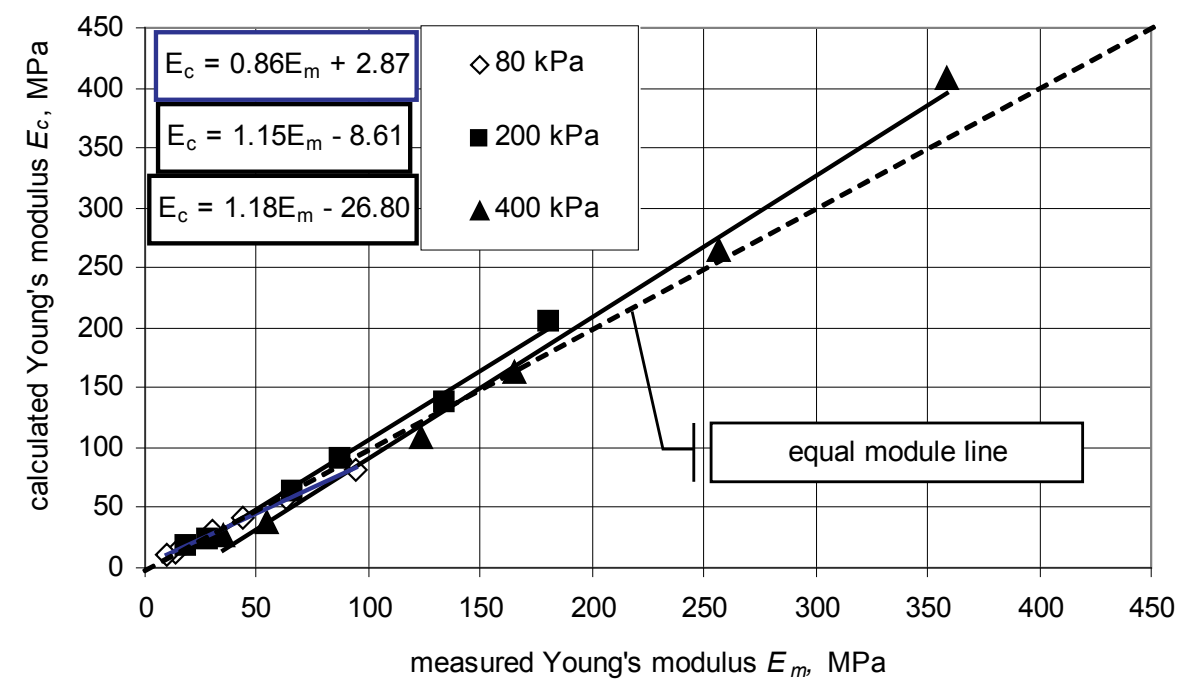

Fig. 10. Calculated vs. measured Young's modulus for undisturbed sandy clays

\section{FINAL REMARKS}

The paper undertakes the problem of stiffness description with account of a key variables contributing to its value. Two soil kinds were selected for the analysis representative for cohesionless and cohesive soils. Dense fine sand and heavy preconsolidated natural sandy clay were tested as very often encountered in Poland. The objective of the paper was to show that it is possible to derive formulae for calculation of Young's modulus for both materials, which accounts for range of strain to which the stiffness is referred. The applicability of the derived formulae covers the intermediate and higher range of strain, i.e., starting from $0.01 \%$ and ending up with $0.5 \%$ in case of cohesionless soils and $1 \%$ for cohesive soils. These are the ranges the most relevant for practical problems. The derived formula for cohesionless soil accounts not only for strain range but also for stress level in wide range of mean effective stress (100-900) $\mathrm{kPa}$. In case of heavy preconsolidated sandy clay it is worth to emphasize that stress level and stress history, which are inherently connected, were accounted for with use of normalization technique. Stress history, represented by yielding stress was determined in triaxial tests with use of new method based on dilatancy concept. In both cases validity of the derived formula was checked by comparison of calculated and measured values of Young's modulus. Convergence of the results satisfies even severe requirements. The formulae can be used not only for practical problems but also for modeling of soil behavior. 


\section{REFERENCES}

BuRland J.B. (1990), On the compressibility and shear strength of natural clays, Géotechnique, Vol. 40(3), 329-378.

Hardin B.O., BLACK W.L. (1968), Vibration Modulus of Normally Consolidated Clay, Journal of the Soil Mechanics and Foundations Division ASCE, 94 (SM2), 353-369.

Jamiolkowski M., LAdD C.C., Germaine J.T., LANCELlOtTA R. (1985), New developments in field and laboratory testing of soils, Proc. 9th Int. Conf. Soil Mech., San Francisco, 1, 57-153.

JARDINE R.J., SyMES M.J., BuRLAND J.B. (1984), The measurement of soil stiffness in the triaxial apparatus, Géotechnique, Vol. 34 (3), 323-340.

Ladd C.C., Foote R. (1974), A New Design Procedure for Stability of Soft Clays, Journal of the Geotechnical Engineering Division, ASCE, Vol. 100, No. GT7, 763-786.

MAIR R.J. (1993), Development in geotechnical engineering research: application to tunnels and deep excavations, Proceedings of the Institution of Civil Engineers, Unwin Memorial Lecture 1992, Civil Engineering, 93, 27-41.

Roscoe K.H. Schofield A.N., Wroth C.P. (1958), On yielding of soils, Geotechnique, 8, 22-53.

SCHOFIELd A.N., Wroth C.P. (1968), Critical state soil mechanics, McGraw-Hill, London.

WDOWSKA M. (2010), Influence of stress history on evaluation of stiffness of cohesive soils, Ph.D. thesis, WULS -SGGW Warszawa. (in Polish - Wptyw historii naprężenia na odkształcalność gruntów spoistych). 